\title{
THE SPATIAL-TEMPORAL ANALYSIS OF ECOLOGICAL ENVIRONMENT OF RED BED HILLS IN EAST SICHUAN - TAKING LU COUNTY AS A CASE
}

\author{
Hanhu Liu ${ }^{1 *}$, Yanyan Liu ${ }^{1}$, XiaoWang ${ }^{1}$, Jingrong Liu ${ }^{1,}$ \\ ${ }^{1}$ Chengdu University of Technology; Chengdu; Sichuan 610059; China - liuhanhu@qq.com
}

KEY WORDS: Ecologic environment,Hilly area,AHP(Analytic Hierarchy Process),RS,GIS

\begin{abstract}
:
Good ecological environment is the foundation of human existence and development, the development of society and economy must be based on the premise of maintaining the stability and balance of the ecological environment. RS and GIS technology are used in this paper while the red-bed hills of Sichuan Province-Lu County have been taken as an example. According to the ecological environment characteristics of the study areas and the principle of choosing evaluation index, this paper selected six evaluation indicators (elevation, slope, aspect, vegetation cover, land use, gully density) to establish evaluation index system of ecological environment of Lu County. This paper determine the weight of each evaluation index by AHP(Analytic Hierarchy Process) and establishes a comprehensive evaluation model by the weighted comprehensive evaluation method. This model is used to divide the ecological environment quality of Lu County into excellent, good, middle, poor and worse, and to analyze the ecological environment change in Lu County in recent ten years.
\end{abstract}

\section{INTRODUCTION}

With the increased intensity of human activities, human beings are changing the global ecological environment with unprecedented scale and speed, and the contradiction between human and land has become increasingly acute.In such a situation, the research of ecological environment has become the forefront and important field of earth science, environmental science and ecology.

Comprehensive assessment of environmental quality is a common method used for understanding and comparison the overall quality of the environment in different periods and different regions(Zhang,2007).This method includes comprehensive index method, fuzzy comprehensive evaluation, gray system method(He et al.2002),landscape ecological method(Liu et al.,2005),matter-element analysis(Wu et al.,2006), artificial neural network(shi et al.,2007) etc. Comprehensive index method (Huang et al.,2008)is one of the most widely used, in which determination of weights is essential. At present, the main method to determine the weights includes delphi method(Wang et al.,2006), analytic hierarchy process(Anselin et al.1989), principal component analysis(Parinet et al.,2002). The Delphi method is called the expert consultation method or expert scoring method.
The traditional methods for observing and evaluating ecological environment are difficult, and it is hard to reflect the changes of the state of the ecological environment in terms of integrity and coherence, so that the problem can not be effectively solved.

Compared with the traditional assessment methods of ecological environment, the combination of remote sensing and GIS technology provides better conditions for the study of regional ecological environment.At the same time, Sichuan red-bed hills is affected by many factors which Include special geological background and hydrology, climate, so that this area has obvious regional characteristics with low water storage capacity, drought. In this paper, the red-bed hills-Lu County is taken as an example, altitude, slope, aspect, land use, vegetation coverage and gully density are selected as evaluation indexes. This paper use AHP to determine the weights and use the comprehensive evaluation model to quantitative evaluate the ecological environment quality condition in Lu County, which provides a theoretical basis for the ecological environment comprehensive treatment and protection as well as implementation of the sustainable development of the region.

\footnotetext{
* Corresponding author: Hanhu Liu
} 


\section{BASIC PRINCIPLE}

This article selects Lu county mining development clusters as the research area, on the basis of sufficient investigation and research, by means of remote sensing and GIS technology to the ecological security research in the study area.Research on the establishment of multi-source remote sensing data processing, mining activity type interpretation signs and information extraction methods;To study information mapping theory, landscape ecology theory as the foundation, the present situation of land use pattern in the studied area and landscape structure complexity and stability analysis of ecological safety evaluation in the study area provide basic data and background information;Based on the Pressure - State - Response (Pressure - State - Response, P - S - R) frame model, follow the "scientific, integrity, pertinence, practicability and induction" principles to establish evaluation index system of ecological security and ecological security in the study area status classification standard;In view of the nonlinear relationship between ecological security situation and evaluation index, artificial neural network model was used to evaluate the ecological security situation of the study area.

The objectives of this paper are to establish the comprehensive eco-environmental assessment system using AHP (Analytical Hierarchic Process) based on the characteristics of eco-environment in Lu County. The evaluation index system is divided into three layers. The first layer takes the comprehensive evaluation of the ecological environment as the target layer. The first layer is the target layer, and the comprehensive evaluation of the ecological environment is the target layer. The second layer is the criterion layer, and the factors are land use, soil erosion index, water system density and topographic landform. The second layer is an index layer, and the factors are elevation, slope direction, slope, valley density, vegetation coverage, land use and water system density.The paper established the ecological environment judgment matrix using a common "1-9" comparison scale method and obtained the weight of index through calculation matrix after the adoption of consistency checking.

\section{METHODS}

\subsection{Study area}

Lu county in Luzhou is located in the southeast of Sichuan province. The east is Yongchuan. The west is Fushun. The north is next to Rongchang. The south is Luzhou Longma district. The actual range coordinates is longitude $105^{\circ} 08$ '30 $"-105^{\circ} 45^{\prime} 30^{\prime \prime}$ and latitude $28^{\circ} 44$ '40 "-29 ${ }^{\circ} 20^{\prime} 00^{\prime}$. In this area, the north-south span is about $47 \mathrm{~km}$ and the east-west span is about $56 \mathrm{~km}$, with a total area of 1532 square kilometers. The whole terrain of Lu County is southwest slower, northeast steep, from southwest to northeast slowly rising, mainly for the hilly terrain and altitude ranges from 184 meters to 714 meters. Regional climate mainly is the subtropical monsoon humid climate, hot and rainy in summer, warm in winter and less rain.

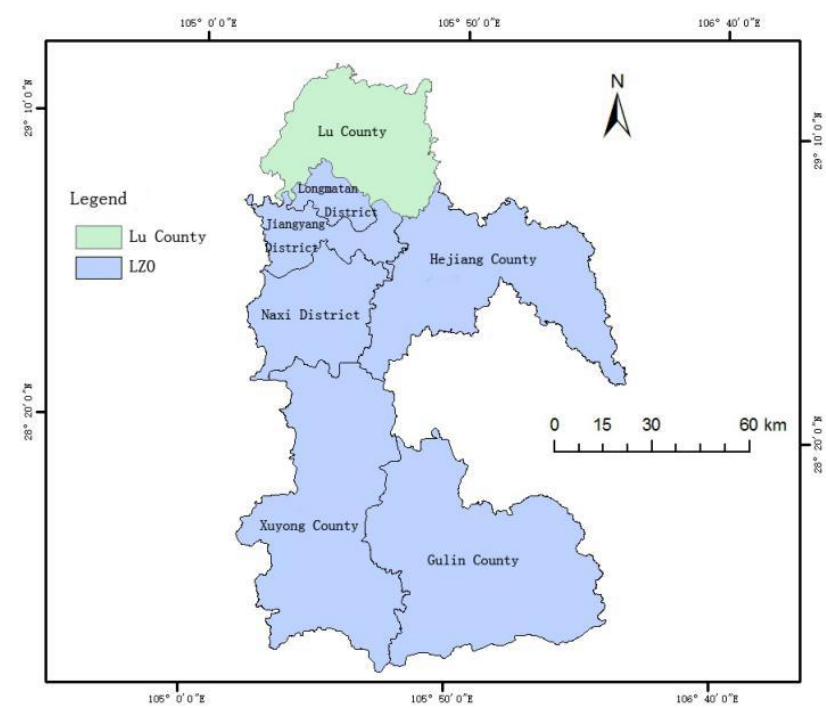

Figure 1 geographical location of the research area.

\subsection{Data and data processing}

Data source includes the Landsat $\operatorname{TM}(2002,2007)$ and OLI(2013) data, DEM data, Sichuan Province administrative plan data.TM remote sensing image data preprocessing includes radiometric calibration, FLAASH atmospheric correction, image stitching and cutting. Because of the different data and projection in different ways, all data use WGS_84_UTM_zone_ $48 \mathrm{~N}$ coordinate system and $30 \mathrm{~m} \times 30 \mathrm{~m}$ spatial resolution to ensure the consistency of evaluation unit and evaluation scale.

\subsection{Evaluation index}

Through the analysis and comparison of the influence of ecological environment quality factors, this paper selected elevation, slope, aspect, vegetation cover, land use, gully density to reflect the impact of the study area topography, soil erosion, land use and human activities.

(1) vegetation cover: The basic methods of calculating the vegetation coverage are mainly those based on the regression model, the vegetation index method, and the dimidiate pixel model. In the dimidiate pixel model, it is assumed that a pixel consists of only two parts-vegetation and non-vegetation. The spectral information is also a linear combination of these two parts, and the proportions of their respective coverages in the pixel give their respective weights; of these, the proportion of vegetation coverage in the pixel is the vegetation coverage of this pixel(Jiang et al,2011 ). Fc is defined as follows:

$$
\mathrm{Fc}=(\text { NDVI-NDVIsoil)/(NDVImax-NDVIveg) }
$$

Where NDVIsoil $=$ zero for most soil types NDVIveg $=$ the maximum of NDVI,

NDVI soil and NDVIveg are different in different Landsat TM/OLI scenes. Firstly, NDVI data of the image were calculated, and the histogram of NDVI data was derived. Secondly, the NDVI value that accounted for $1 \%$ of pixels of the histogram was set as NDVI soil, and the NDVI value for $99 \%$ of the pixels was set as NDVIveg. Finally, the NDVI soil and NDVIveg values were put into Eq. (3).

(2) Land-use: The first, supervised classification is used to class land-use. Then, using image of TM4,3,2 bands synthesis visually modify obvious classification error area .Finally ,the 
land-use type in the study area is divided into woodland, paddy field, dry land, traffic land, urban land and water area.

(3) Gully density: DEM is used to extract flow direction by filling depressions, flow accumulation and distribution of gully valley by the valleys extraction method of setting a threshold. The kilometer grid of study area automatically generated by GIS. Overlay analyzing grid distribution graph and gully distribution diagram to statistics gully length on each grid, This length divided by the grid area to obtain the gully density.

(4) Other: Elevation, slope and aspect are calculated by DEM.
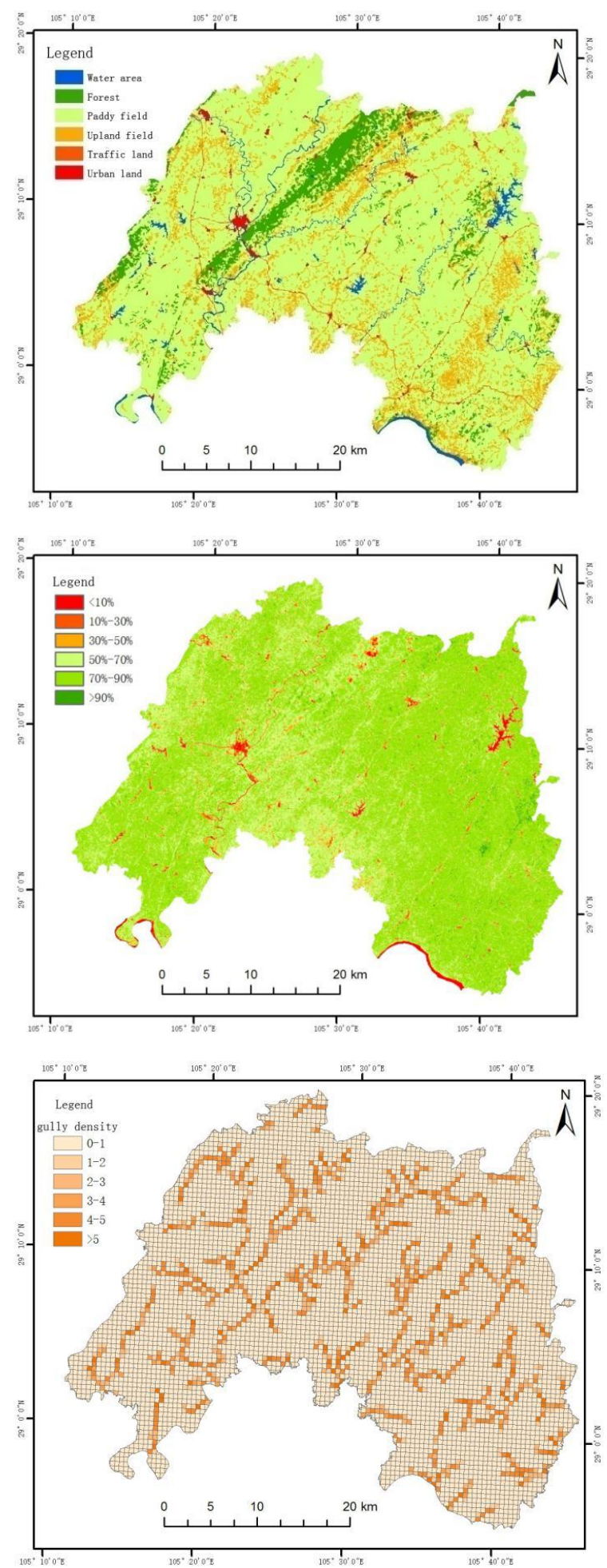
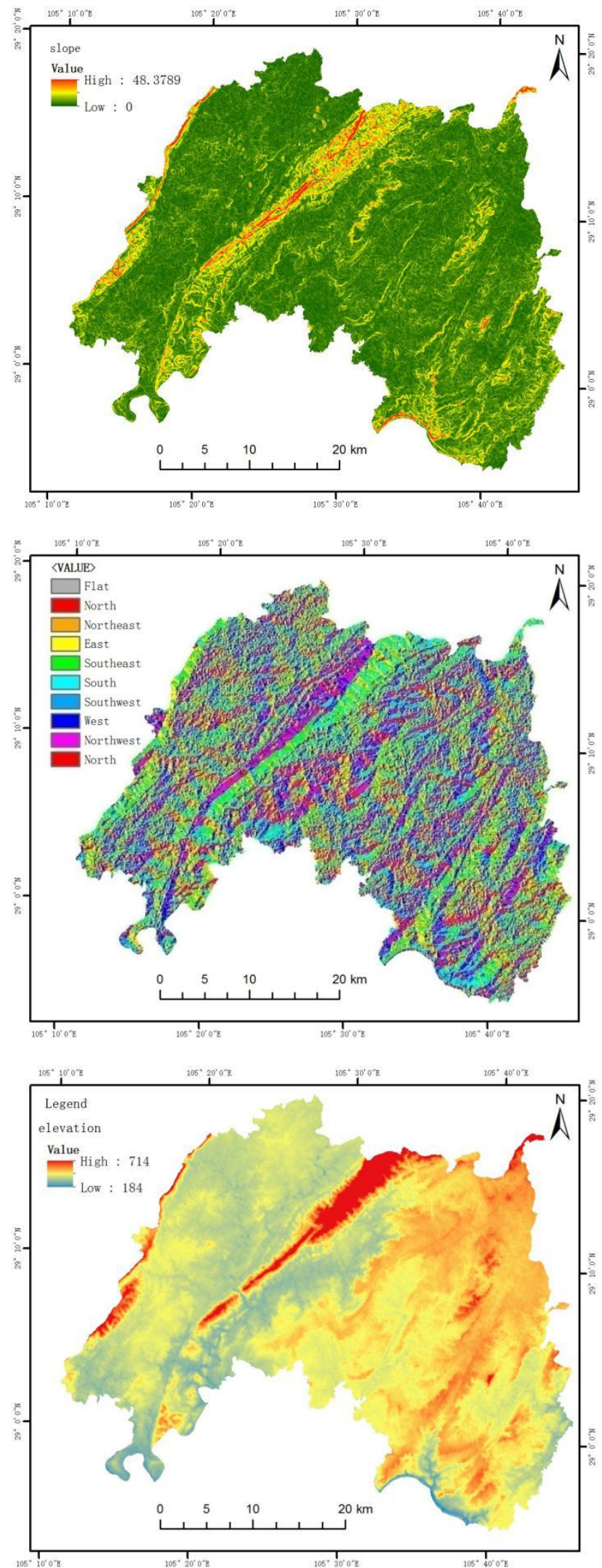

Figure 2 evaluation index(a:land us map;b:vegetation coverage;c:gully density;d:slope;e:aspect;f:height )

\subsection{Model}

To obtain further information of ecological environment quality in the study area, we need to select the appropriate evaluation to 
comprehensive evaluate the information. This research adopts the method of weighted summation to constructing the evaluation index of ecological environment quality.

The formula:w is ecologic environmental quality index of evaluation unit; $\mathrm{n}$ is the total number of evaluation factors; $\mathrm{R}$ (i) is the weight of each evaluation factor value' $X(i, j)$ is factor generalized normalization data of each evaluation.

Using the analytic hierarchy process (AHP) to determine the weights of evaluation factors. The analytic hierarchy process turn the comparison between the multiple factors to the comparison between two factors. Judgment matrix of factor importance(Table 1) is constructed by consulting relevant experts, referring to the existing research results and data, analyzing of ecological environmental quality distribution,comparing importance between two factors, assigning each factor. Then, ecologic environmental quality evaluation of multiple factors model is established by using hierarchical analysis method to calculate the weight of each factor.

\begin{tabular}{|c|c|c|c|c|c|}
\hline $\begin{array}{l}\text { Target } \\
\text { layer }\end{array}$ & \multicolumn{2}{|c|}{$\begin{array}{l}\text { The criterion } \\
\text { layer }\end{array}$} & \multicolumn{2}{|c|}{ The index layer } & \\
\hline \multirow{7}{*}{$\begin{array}{l}\text { The } \\
\text { compr } \\
\text { ehensi } \\
\text { ve } \\
\text { evaluat } \\
\text { ion } \\
\text { index } \\
\text { system } \\
\text { of } \\
\text { ecologi } \\
\text { cal } \\
\text { enviro } \\
\text { nment }\end{array}$} & $\begin{array}{l}\text { First } \\
\text { grade }\end{array}$ & weight & $\begin{array}{l}\text { Second } \\
\text { grade }\end{array}$ & weight & $\begin{array}{c}\text { Data } \\
\text { source } \\
\mathrm{s}\end{array}$ \\
\hline & & & Aspect & 0.0449 & DEM \\
\hline & $\begin{array}{l}\text { Topogr } \\
\text { aphy }\end{array}$ & 0.3169 & Elevation & 0.0308 & $\overline{D E M}$ \\
\hline & & & Slope & 0.2412 & $\overline{\mathrm{DEM}}$ \\
\hline & $\begin{array}{c}\text { Soil } \\
\text { erosion } \\
\text { intensit }\end{array}$ & 0.5235 & $\begin{array}{l}\text { Vegetation } \\
\text { coverage }\end{array}$ & 0.3517 & $\begin{array}{l}\text { Remo } \\
\text { te } \\
\text { datas }\end{array}$ \\
\hline & $\mathrm{y}$ & & $\begin{array}{l}\text { Gully } \\
\text { density }\end{array}$ & 0.1718 & DEM \\
\hline & $\begin{array}{l}\text { Land } \\
\text { use }\end{array}$ & 0.1596 & Land use & 0.1596 & $\begin{array}{l}\text { Remo } \\
\text { te } \\
\text { source }\end{array}$ \\
\hline
\end{tabular}

table 1 The weight of comprehensive evaluation of ecological environment

\section{RESULTS AND DISCUSSIONS}

On the platform of arcgis, the indexes are transformed into raster data formats, using GIS spatial overlay analysis to calculate ecological environmental comprehensive index of each grid, the environmental quality is quantitative evaluated. The calculation formula is as follows:

Ecological environmental index $=$ land use $0.1596+$ vegetation coverage $0.3517+$ slope $0.2412+$ gully density $0.1718+$ aspect 0.0678 + altitude 0.0308

The resulting value represents the quality of ecological environment, greater numerical representation of the better ecological environment condition. On the contrary, the smaller the resulting value is, the worse the ecological environment situation is.
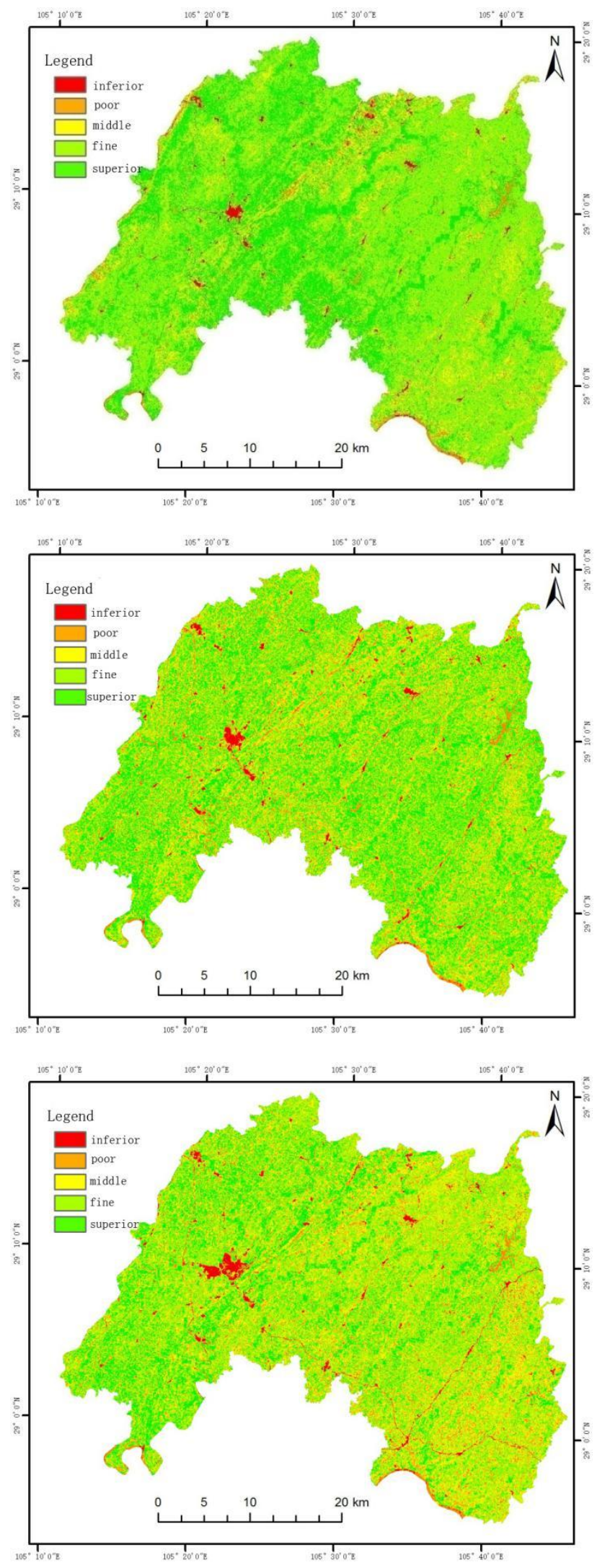

Figure 3 ecological environment assessment diagram in Lu county(a:2002;b:2007;c:2013)

As we can see from the figure 3, the ecological environment of Lu county is good as whole, except counties and urban areas in 2002. But, in 2007, the poor areas have obvious nodular and 
linear features, mainly affected by building land and highway land. In 2013, the poorer area is further expand, the surrounding ecological environment of rural settlements became worse and worse.

The statistical function of arcgis is used to calculate figure 4.

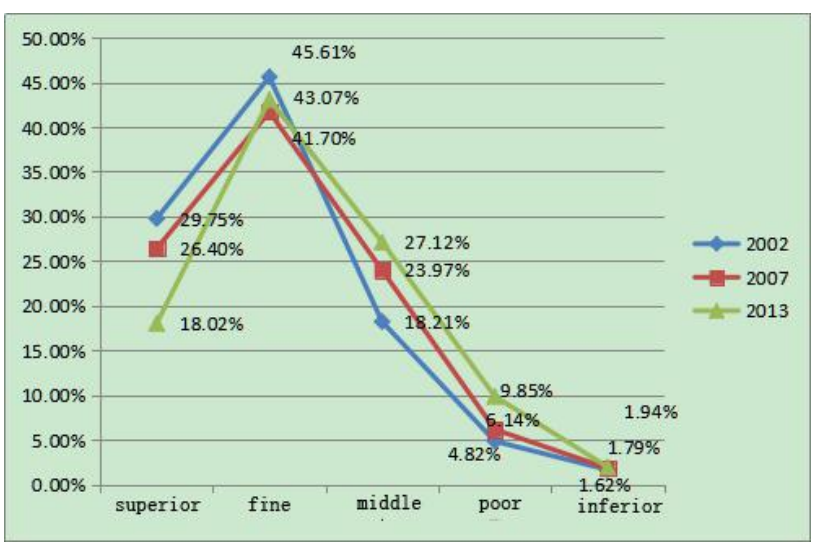

Figure 4 ecological environment area scale map in Lu county

As we can see from figure 4 , in the 2002-2013 ten years, the ecological environment quality deterioration in the overall reginal. In 2002, the environment quality is excellent accounted for $29.75 \%$, reduced to $26.40 \%$ by 2007 and reduced by $2.35 \%$.Compared with 2007 , the area of excellent environment quality is only $18.02 \%$, reduced by $8.38 \%$ by 2007 and changing significantly faster. The study area of good, fair, poor ecological quality had increased overtime, Therefore, the regional ecological environment is deteriorating.

\section{CONCLUSIONS}

Study area is located in the Sichuan Lu county red-bed hills. This area is affected by many factors in special geological background and hydrology, climate, so that this area has obvious regional characteristics-land without water storage capacity, drought and water shortage.

In this paper, AHP, the establishment of ecological environment comprehensive evaluation system and the weighted sum model method is used to construct the ecological environment quality evaluation index.

The quality of Lu county environment quality overall is good, only poor ecological environment in county and town in 2002. in 2007,the ecological environment quality poorer area are has obvious nodular and linear features, mainly affected by building land and highway land. In 2013, the ecological environment quality poorer area is further expand, the surrounding ecological environment of rural settlements further deteriorate.

In the 2002-2013 ten years, the ecological environment quality deterioration in the overall reginal. The study area of good, fair, poor ecological quality had increased overtime, Therefore, the regional ecological environment is deteriorating.

\section{REFERENCE}

Grainer,VALZ,2000 a.Development of Environmental Indieator Systems:EXPerienees from Germany], Environmental Management,25(6),pp.613-623.
Liu Xue,2006 a. cheng-tai diao, such as huangjuan. Regional land resources security evaluation, soil and water conservation bulletin, 24 (5),pp.57-61.

Muller F, Hofl'maun-ICroll R and Wiggering H,2000 a. Indicating Ecosystem Integrity-theoretical Concepts and Environmental Requirements .Ecological modeling,130,pp.1323.

Noss R F High-risk Ecosystems as Foci for Considering Biodiversity and Ecological Interity in Ecological Risk Assessments .Environmental Seience\&Poliey, 23,pp.321-332.

Sutllerland W J,1999 a. Assessmg Ecosystem Health.TREE, 14(3),pp.69.

Tao hong, MAO xi, dai fuchu, etc,2007 a. Based on GIS, comprehensive regional study on mining geology in shaanxi province . Geological disaster and.Environmental protection, 18(2),pp.42-45.

Vanclay J K and Skovsgaard J P,1997 a. Evaluating Forest Growth Models .Ecological Modeling, 1997(98),pp.1-12.

Wu qiang, Chen qi,2008 a. Study on environmental effects induced by mine environmental problems . Hydrogeological engineering geology,5,pp.81-85.

Wang yongsheng,2006 a. Problems and countermeasures of mine environmental management in China . Western resources,(5),pp.32-33.

Xinhuanet.,2008.Shanxi XiangFen dam accident death toll rose to 262 people.http://news.Jlnhuanet.eom/newseenter(18 September 2008) 